\title{
Strategies for Promoting the Value of Tourist Cultural and Creative Brands Based on Cultural Elements
}

\author{
Chunhua Zhao \\ School of Fashion Communication, Beijing Institute of Fashion Technology, Beijing, China
}

\begin{abstract}
Tourist cultural and creative brands are the condensation of culture, history, design and commerce. In the collision and blending of culture and commerce, it forms unique competition advantage. The developers of tourist cultural and creative products, based on the cultural core, explore and construct the symbolic meaning, and help tourists to complete the aesthetic journey from viewing to purchasing and then to cultural experience. In the brand strategy, developers should base on the cultural foundation, construct symbolic meaning and cultural image, and implant cultural association into products through traditional cultural inheritance and innovation, so as to arouse consumers' cultural identity and strengthen the brand value.
\end{abstract}

\section{Introduction}

Integration and innovation of culture and tourism is a new trend in the development of commercial products. Tourist cultural and creative brand integrates culture, history, art, science and commerce. In the collision and integration of culture and commerce, tourist cultural and creative brand has become a unique commodity form.

Brand value is the core of brand equity and the essence of a brand. It is also an important symbol that distinguishes a brand from competitive brands of the same sort. A brand is a name, term, symbol or design, or the combination of the above, which distinguish a product or service from those of other competitors [1]. The Theory of Relationship emphasizes that brand exists and develops because of the relationship between products or services and consumers, rather than just a system of recognition. Brand consumption becomes a way for consumers to express themselves, seek emotional belonging and group identity. Brand is a series of functional and emotional value elements [2]. In the process of building brand value, its core motivation and spiritual source mainly comes from brand culture. Viewing the world famous brands, most of them are deeply rooted in their culture, in the expression of cultural connotation on the continuous excavation and interpretation.

For consumers, cultural creative brand is the quality symbol and technical guarantee of cultural products [3]. Compared with ordinary brands, cultural and creative brands have more profound cultural deposits in addition to their general commercial characteristics.

As a complex and advanced social and economic activity, tourism contains both spiritual and material elements. It is both a social and cultural phenomenon and an economic phenomenon. In order to obtain a cultural aesthetic experience, tourists have completed the upgrading from viewing to purchasing and then to cultural experience. Tourism not only has the function of inheriting social culture, but also has the special commercial value. Especially when tourism is co-media with culture, it forms a cultural consumption dominated by deep spiritual value, which provides a solid support for the promotion of brand value.

\section{The Cultural Attributes of Tourist Cultural and Creative Brands}

Tourist cultural and creative products are tourist products (including tourist souvenirs) with cultural connotation and creativity. Their core lies in innovatively transforming culture, with products as the carrier, thus enriching consumers' spiritual needs [4]. Culture-centered innovative design is the soul of the product. In the differentiation competition in the business area, this attribute composes strategic advantage.

Cultural elements are the core elements of cultural and creative products. The products without cultural connotation and cultural origin, in a certain sense, are lack of commercial value. In the field of tourism, successful brands usually have profound cultural connotations and their products present strong cultural symbols. "The national belongs to the world". The essence of this saying shows that any product, if separated from its unique cultural settings and national characteristics, will be difficult to obtain the recognition and respect from the world. In another sense, the process of artistic products created by human beings is a process of constantly exploring, discovering, recording, inheriting and creating its cultural symbols. Culture, as the expression form of human civilization, has become an important carrier of human inner belongings and spiritual dependence. Cultural and creative products, as their external form, cannot be separated from their cultural roots. Tourist 
cultural and creative products, as commodities with artistic and creative characteristics, cannot be completely separated from their cultural attributes.

Tourist activity is a kind of experiential behavior, and experience is the core of tourism. From the content and means of tourist experience, the whole process is actually a process of cultural blending. Once we have understood that tourism is an interactive process in which individuals communicate with nature and society, the tourist experience will have distinctive cultural characteristics and symbolic significance. The interpretation of this cultural and even symbolic system also means the reconstruction of this system. Therefore, the attention to this system is of great significance for social construction [5].

\section{Cultural Attributes Enhance the Brand Value of Tourism Cultural and Creative Brands}

Cultural attributes endow tourist cultural and creative products with strong discrepancy. The upgrading of tourist process from sightseeing to purchasing goods and then to cultural experience makes the cultural and creative products more symbolic and identifiable and the brand's premium power and sales power are greatly enhanced.

\subsection{Cultural Attributes Improve the Symbolic and Identification of Tourist Cultural and Creative Products}

The process of tourist experience is a process of interpreting symbols. The attraction and appeal of tourism comes from the symbolic significance of tourism itself. In essence, tourism consumption is a kind of symbolic consumption, which forms tourist motivation based on the attraction of indicative symbols, and thus the tourist experiences and obtains emotional satisfaction in a symbolic environment. John Urry notes in The Tourist Gaze: Leisure and Travel in Contemporary Societies (1990): Everything the traveler views is made up of symbols that signify something else. Under the gaze of tourists, all landscapes are endowed with symbolic meanings and become cultural landscapes [6].

Today, people are increasingly inclined to the symbolic consumption. The purpose of people's consumption is no longer to meet the needs of survival, but to achieve higher spiritual purposes. Symbolic value expresses style, prestige, power, etc., which has become an important part of commodities. Objects are no longer purchased for their intrinsic value (including use value and exchange value), but for the symbolic value they represent [7].

Tourist landscape is a "living" cultural symbol closely related to human survival and development, and a symbol of local culture, which contains a nation's ancient life memory and a living cultural gene pool [8]. Culture is an important carrier of a nation's national spirit, national emotion, individual characteristics, cohesion and affinity, and has national characteristics. The culture of each nation has its unique creativity and value which is different from that of the others. It is an independent system which cannot be repeated and replaced. The cultural symbol characteristics of tourism make its related products have a very strong identity.

\subsection{Cultural Elements Enhance the Premium Capacity of Cultural and Creative Brands}

Cultural and creative products, which reflect the uniqueness of tourist resources and regional culture in scenic spots, are important carriers of tourists' travel experience and memory. Moreover, because of their strong connotation of cultural symbols, they are easy to form emotional emotion, which bring strong brand premium ability.

Brand premium is an essential means to strengthen the value of tourist brands. Through cultural empowerment, brands get a higher price than the average, which becomes a powerful approach for higher price, higher profit rate [9]. Premium capacity mainly depends on tourists' emotional factors. Tourists are willing to pay more than the standard price for travel goods because of their emotional value. Tourism embodies the experiential value of education, aesthetic appreciation, seeking roots, nostalgia and curiosity. Emotional satisfaction is the direct embodiment of cultural value to a great degree, which can highly promote the tourists' feelings towards the scenic spots.

By touching the emotional appeal of tourists, it makes them form symbolic images and cultural induction. In the process of value transmission and formation, the importance of emotional appeal is self-evident. Information that is not emotional, no matter how high its information value, is difficult to settle down in the brain. The value of cultural elements lies in the fact that they arouse the audience's emotional appeal through symbol communication and enhance the tourists' preference and emotional affiliation to the tourist spots. When tourists identify with the cultural phenomenon and cultural connotation of the tourist destination, they will invest more emotion in it, which enhances the commercial value of tourist cultural and creative brands and then composes repeated consumption.

\subsection{Cultural Association Enhances Brand Identity}

Cultural association enhances brand identity. Because of the visual and creative presentation of artistic aesthetics, ethnic elements and cultural symbols, cultural association provides a channel for brand identity. This is conducive to the formation of brand preference and loyal consumption.

Tourist souvenirs create plenty intangible cultural associations and images higher than others, which make tourists believe their long history, rich cultural connotation, unique memory or viewing experience. Eventually, It is the emotional factor of consumers that promotes the purchase behavior. Therefore, creating symbolic association and arousing tourists' emotional attention have become a key part of brand strategy.

With the improvement of people's living standard, tourists not only stay in the functional standard of 
practicality of production and living, but also pay more attention to highlight their taste and personal value through the aesthetic and cultural value of goods. The emotional value of cultural and creative products is emphasized, and the value of cultural attributes is further enhanced. Under the setting of cultural and tourism integration, as the product of the organic combination of tourism industry and cultural and creative industry, tourist cultural and creative products not only show the resource characteristics of scenic spots, but also promote the cultural characteristics of scenic spots, and transfer the cultural essence between regions and ethnic groups through the form of tourist products, and finally consolidate the brand identity.

\section{The Path to Promote the Brand Value of Tourist Cultural and Creative Products}

\subsection{Build Symbolic Meaning and Cultural Image Based on Cultural Essence}

Culture is national treasure handed down from generation to generation. It carries the ideological essence and cultural concept of a nation, and is the core of a nation's symbolic system. It contains unique spiritual connotation of the nation. Culture is presented in the form of fragments, so that tourists stay on the surface of participating in a certain cultural fragment, but fail to understand the overall cultural picture and deep cultural spiritual connotation behind the fragment [10]. Symbols are the breakthrough to reflect the overall cultural value in the products. Cultural symbols are the internal operating mechanism of brand communication, just like the blood of a brand, which affects the vitality and effectiveness of the material system all the time. For example, the patterns, styles and colors represent the meaning, convey the concept and connotation of the brand. The visual influence exerted on the audience in the process of meaning transmission determines the value of the brand.

Developers of tourist cultural and creative products can explore and construct symbolic meanings based on the cultural core. By referring to and sorting out various historical documents related to the nationality of the tourist spots, by classifying and restoring the architectural patterns and extracting the cultural patterns, the essence of culture is extracted, and identifiable and recoverable cultural symbols are formed. At the same time, on the basis of grasping the essence of culture, creative planning is carried out, various cultural elements are integrated, and the characteristic national cultural symbols and images are re-coded in the modern aesthetic background. In this way, tourists obtain spiritual satisfaction and cultural support, and form a cultural association. Only in this way can we create tourist cultural and creative products with a real cultural core.

In addition, developers are supposed to study and explore the symbolic meaning of the scenic spot culture, and to avoid simplification and misleading of symbolic interpretation and design. At present, some developers are tent to superficial design and ignore the cultural connotation of cultural and creative products. The products turn to be a kind of crude and boring cheap products, whose aesthetic and culture value are greatly reduced.

\subsection{Design Strategy of Tourist Cultural and Creative Brands with Cultural Elements as the Core}

Cultural and creative products themselves are the embodiment of culture, and at the same time, they are also creating new cultures. Designers, through their own creative behavior --- cultural and creative product design, dig deep into the connotation of cultural elements and present cultural elements to consumers in a concrete form, thus materializing cultural characteristics [11].

Cultural and creative product design is the crystallization of regional culture, traditional culture, national culture and the culture of the era. Designers take traditional culture as the foundation and develop cultural and creative products with cultural symbols. In this way, on the basis of the integration of cultural elements into the new artistic form, designers can not only pass on the multi-culture to consumers, activate the cultural value, but also enable consumers to obtain cultural pride and cultural identity, virtually enhance the emotional value of the brand.

Take "the Cultural and Creative Products of the Palace Museum" (abb. CCPPM) as an example, the core of which comes from the artistic deposits of China's royal culture. Its inspiration stemmed from the Ming and Qing dynasties royal culture. Through deep mining, combing historical allusion and historical origin, recovery of representative royal art designs and color, CCPPM utilize aesthetic symbols in the design of the products and guide the consumers to experience the appeal of the traditional art.

For example, Bookmark of Riverside Scene at Qingming Festival in Figure 1 is inspired by the ancient painting collected in the Palace Museum. Its style, pattern and color enhances the aesthetic sense of the product, making it elegant and unique.

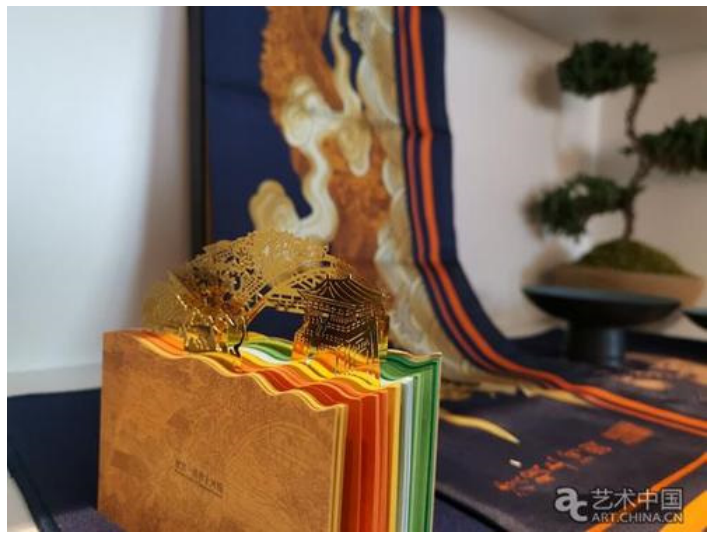

Fig 1. Bookmark of Riverside Scene at Qingming Festival

The origin of cultural brands comes from historical and cultural precipitation, while the breakthrough of the 
value comes from consumers' cultural impression and traditional aesthetic experience. Value in brand association and cultural aftertaste constantly improve.

\subsection{To Enhance the Sense of the Times and Popularity}

The modern design of traditional symbols can promote the popularity of cultural and creative products. Traditional culture and modern trends sometimes alienate. The rigid copy of ancient cultural and artistic style into the design of modern products will produce culture shock. The brand image and acceptability of cultural and creative products are influenced by how to harmoniously integrate the ancient and the modern, and how to inherit and innovate with modern aesthetics.

For example, in figure 2, the Palace Museum and Harper's bazaar have teamed up to launch "the Palace Museum - Bazaar Red", a exquisite blessing necklace set. It actively apply modern cultural elements, create collision between tradition and modern sense, and especially consider the cultural preferences of the younger generation, and then form the characteristics of the palace product design. The product includes a long "Exquisite Blessing" necklace, a Bazaar red lipstick and a "Cliff along the Sea" handbag. The sparkling red impresses the consumers at the first sight, and the traditional pattern "cliff along the sea" makes its appear ancient and elegant. The traditional color of such a large slice does not make the product old or boring. On the contrary, when the traditional symbols collide with modern design, it creates magic effect.

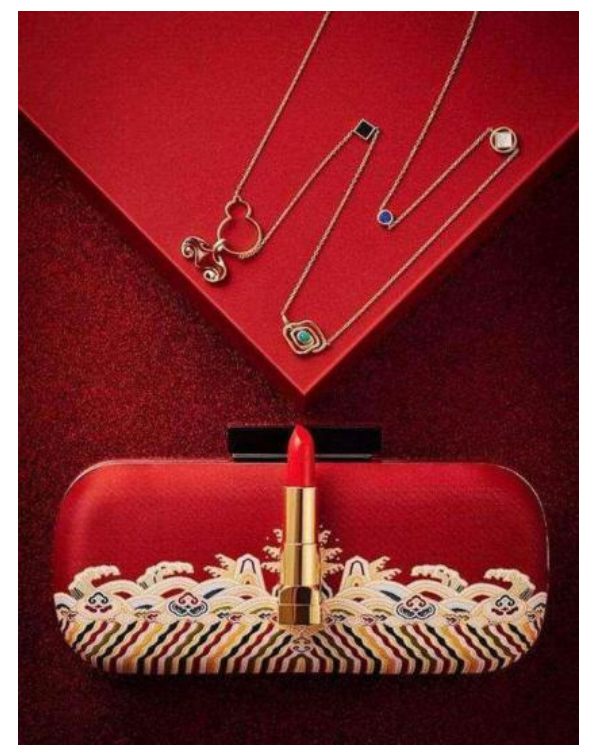

Fig 2. the Palace Museum "Exquisite Blessing" Necklace Set

This cultural and creative product contains both grace of the palace style and the strong modern sense. It not only contains a strong Chinese style, but also has an eyecatching sense of modern design. Thus, the Chinese style has become a fashion product. It produces good effect to brand reputation, image and association.

\section{Conclusion}

Tourism cultural and creative products are the condensation of culture, history, design and commerce. The developers are supposed to explore and construct the symbolic meaning on the basis of the cultural core, and to help the tourists to complete the aesthetic journey from sightseeing to purchasing and then to cultural experience. With the culture as the inspiration, the design of tourist cultural and creative brand stand more chances to reach originality and composes distinctive brand recognition and identification. Thus, the premium capacity of the brand is highly promoted and the brand value is eventually enhanced.

\section{Acknowledgments}

This paper was the phased research results of the Social Science Project of Beijing Education Commission (No. : SM201810012003) and the Special Fund Project for the Construction of High-level Teachers Team of Beijing Institute of Fashion Technology (No. : BIFTTD201803).

\section{References}

1. He Jiaxun, Brand Image Planning (Shanghai: Fudan University Press, 5-6, 2000).

2. J.Chernadoni, Brand Winning: From Brand Outlook to Brand Evaluation (Beijing: CITIC Publishing House, 2,2002).

3. Bai Dingguo, Brand Culture (Changsha: Hunan Normal University Press, 53,2010).

4. J. Yang, Cultural and Creative Industries (CCI) and Sustainable Development, China's Cultural Industries Clusters, PP, 5, 231-242 (2017).

5. Deng Xiaoyan, The Path Choice of Intangible Cultural Tourism Development in the Context of Symbol Consumption, GSS, 4, 38-39 (2010).

6. Urry John, The Tourist Gaze: Leisure and Travel in Contemporary Societies (London: Sage, 129,1990).

7. Yang Boxu, Li Lingling, Evolution of Capitalist Consumer Culture, the Role of Media and Globalization, JJCR, 1, 38-40 (2001)

8. Wang Jushan, The Impact of Cultural Nationalism on the Protection of Intangible Cultural Heritage, JZNU (Social Science Edition), 1, 70-73 (2009).

9. Zhao Chunhua, Fashion Communication (Beijing: China Textile Press, 84-86, 2018).

10. Sun Jiuxia, Transplantation of Ethnic Culture: Interpretation from the Perspective of "Tourist Stare", I F,4, (2009).

11. Li Hongchao, Wang Xinyu, Li Weiyu, Research on Cultural and Creative Product Design of the Palace Museum Based on Cultural Elements, PE, 2021. 